\title{
Multidimensional value creation through different reverse supply chain relationships in used clothing sector
}

Rudrajeet Pal, Erik Sandberg and Manoj Kumar Paras

The self-archived postprint version of this journal article is available at Linköping University Institutional Repository (DiVA):

http://urn.kb.se/resolve?urn=urn:nbn:se:liu:diva-161607

N.B.: When citing this work, cite the original publication.

Pal, R., Sandberg, E., Paras, M. K., (2019), Multidimensional value creation through different reverse supply chain relationships in used clothing sector, Supply chain management, 24(6), 729-747.

https://doi.org/10.1108/SCM-12-2018-0422

Original publication available at:

https://doi.org/10.1108/SCM-12-2018-0422

Copyright: Emerald

http://www.emeraldinsight.com/ 


\title{
Multidimensional value creation through different reverse supply chain relationships in used clothing sector
}

\begin{abstract}
Purpose: This paper purports deeper understanding of, and instigates theoretical elaboration to, multidimensional value created through different reverse supply chain relationships.

Design/methodology/approach: By capturing the relationships (and their differences) constituted and embedded in three "extreme" case studies from global used clothing supply chain, the sources of multidimensional values are explored in line with Dyer and Singh (1998)'s relational theory.

Findings: In the reverse supply chain, when downstream relationships are typically more opportunistic, value is created using inter-personal ways of knowledge sharing, and through use of informal safeguards. In contrast the upstream RSC relationships are more symbiotic, and value is created through more seamless (and routinized) knowledge sharing practices, and additional use of more formal transaction-specific controls or financial incentives as safeguarding instruments.
\end{abstract}

Research limitations: The use of consolidated case studies may affect the consistency in the findings presented. Another limitation relates to deriving propositions per each source presented in relational theory.

Practical implications: Practitioners particularly from industries whose global reverse supply chains include different natures of relationships and multiple value incentives can be benefited through this study.

Originality/value: The paper extends the original sources of value creation prescribed in relational theory by contextualizing them in reverse supply chains. It depicts how multidimensional values are created relationally by dyadic partners as the nature of relationship differs between upstream and downstream.

Keywords: Reverse supply chain, Value creation, Relational theory, Clothing, Case study.

Article classification: Research paper 


\section{Introduction}

In the recent years, opportunities for value creation and gaining competitive advantage in reverse supply chains (RSCs) have been largely recognized in scholarly literature, amidst the increasing demands for sustainability and circular economy (e.g. Beh et al., 2016; Erol et al., 2010; Larsen et al., 2018). Amidst this growing strategic importance of RSCs, with its roots in reverse logistics, firms have strived towards developing distinctive capabilities for higher value creation (Jack et al., 2010; Jayaraman and Luo, 2007; Skinner et al., 2008). In light of understanding such value creation in RSCs, previous research highlights the role of resource commitment for generating both economic and environmental values (Huang et al., 2012; Richey et al., 2005). Such resource commitment is not only dependent on firm's internal strategic resources and capabilities (Jayaraman and Luo, 2007; Li and Olorunniwo, 2008), but prior RSC studies have equally emphasized the key role of developing collaborative relationships, such as cross-functional integration, IT-enabled buyer-seller relations, that can further enhance the value creation potential (Beh et al., 2016; Morgan, 2016; Xie ad Green, 2012). In fact, such values are accrued jointly through generation of boundary-spanning, inter-organizational resources, i.e. through creation of shared assets or resource complementarities, and thus highlight the core tenets of relational view of firms (Dyer and Singh, 1998; Lavie, 2006).

In RSCs, such collaborative relationships between firms take various dyad types, e.g. simpler buyer-seller or supplier-customer transactions (Aitken and Harrison, 2013; Son et al., 2015) to more strategic collaborations (e.g. as proposed in Lau and Wang, 2009; Olorunniwo and Li, 2010; Simpson, 2010), and in connection adopts diverse governance mechanisms, exemplified by trust or formal contractual arrangements (Aitken and Harrison, 2013; Jack, 2010). Moreover such relationships in RSCs are a source of multidimensional values e.g. economic, environmental, image for firms created relationally (e.g. Morgan, 2016; Sandberg et al., 2018; Xie ad Green, 2012). However, previous studies have mostly examined such value creation in single type of dyads (mainly buyer-seller type) taken individually as the unit of analysis, thus what we find in reviewing RSC literature is limited understanding of how different types of relationships, with their distinct characteristics, influence multidimensional value creation in RSCs. In this context, by capturing the different collaborative relationships (and their differences) constituted and embedded in three "extreme" cases from global used clothing RSCs, this paper purports deeper understanding of, and instigates theoretical elaboration to, multidimensional value created relationally in RSCs. The sources of these values are derived in line with Dyer and Singh (1998)'s seminal work on relational theory (RT), in order to answer how multidimensional values are created through different reverse supply chain relationships?

The clothing industry being one of the world's most polluting industries, has received growing attention in terms of its reverse practices, hence constituting a rich empirical ground for research. Typically the used clothing RSC is a complex, global-distributed, multi-tiered commodity chains, that spans between Global North-South, and consists of diverse members, such as non-profit charity organizations, sustainability-driven fashion retailers and also more commercially-oriented firms (e.g. sorters, brokers and specialized processers) (Brooks, 2013; O'Reilly and Kumar, 2016; Sandberg et al., 2018). Sandberg et al. (2018) depict this RSC as a series of complex reverse activities, such as acquisition, grading, re-processing, and redistribution, and as the used clothes flow from Global North (referred as upstream, from now on) to Global South (referred as downstream, from now on) they get renewed with a new value for new purposes and customers. The customers of this RSC typically range from vintage clothes retailers to charities, but also include other industries such as automotive, in 
which reused/recycled clothes are used for filling and insulation. In addition, fashion retailers and their manufacturers are also becoming customers of recycled fibres (O'Reilly \& Kumar 2016). To demonstrate the volume of this industry, some recent statistics present the value of used clothing exported from the U.K., ranked as the world's second biggest exporter, in 2017 to be 507.96 million U.S. dollars (Statista, 2019), while the overall global trade amounts to nearly 4 billion U.S. dollars (Acharya 2015). Further U.K. totalled 3,994 stores specialized in selling second-hand clothes with the value of used clothing imported worth approximately 61.36 million U.S. dollars. Such used clothing RSCs are exemplified by the presence of many dyadic relationships and with different underlying incentives, e.g. between for-profit and nonprofit actors. Additionally, a diverse range of values are comprehended by these actors - from customer satisfaction value to environmental value (Pal, 2017; Sandberg, et al., 2018). Focusing on this industry in essence allowed us to cover this compounded relational view as mentioned above, thus beneficial for theory elaboration.

The remainder paper is structured as follows: starting with a theoretical background to RT in RSC context, the abductive research methodology and cases are presented. This is followed by within-case and comparative case analyses in line with Dyer and Singh (1998)'s four sources of relational value. The comparative analysis yields four propositions which are then discussed and necessary conclusions are drawn to highlight the scope for future research.

\section{Theoretical background: a relational view of RSC}

This study builds on the fundamental concepts of multidimensional value creation and relational dyads, in RSCs as presented below.

\subsection{Multidimensional value creation in RSCs}

Value creation in RSC is based on the idea of turning 'waste' into valuable component for developing new products, primarily through a set of efficient reverse logistics activities, that include acquisition, grading, re-processing, and re-distribution (Guide and Van Wassenhove, 2009; Jayaraman and Luo 2007). It has been established that such activities are essential for not only reducing total supply chain costs (Bernon et al., 2011; Jack et al., 2010), but also to improve customer satisfaction and increase customer value (Jack et al., 2010; Skinner et al., 2008). Thus the values created are multidimensional; specifically Jayaraman and Luo (2007) and recently Schenkel et al. (2015a) and Pal (2017) have identified five major categories of value that can be created in reverse and closed-loop supply chains. These are: (i) economic value - cost reduction, revenue generation, productivity, efficiency, (ii) information value transparency, market knowledge, (iii) customer value - customer satisfaction and loyalty, consumer awareness, convenience, trust, (iv) environmental value - resource efficiency, green product-process and logistics, waste reduction and landfill prevention, and (v) image value corporate citizenship, green image, corporate social responsibility.

In order to realize these values, previous studies have identified both intra- and interorganizational enablers of good RSC design. Important intra-organizational enablers, amongst others, are strategic acquisition of 'waste' (Hazen et al., 2012), 'proper' sales channel structure (Bernon et al., 2011), and post-retail communication strategies (Jayaraman and Luo, 2007). For instance, strategic and consistent acquisition results in collection of the best quality material with low variability thus ensuring better economic value for the collector, which further ensures higher product reusability and long-term relationship with members downstream (i.e. customer value) (Schenkel et al. 2015). For a detailed exposé of intraorganizational value creation in RSC, see Jayaraman and Luo (2007). On the other hand, key 
inter-organizational enablers are mainly related to collaboration for undertaking RSC activities (Bernon et al., 2011). Simpler arm's length relationships as developed through outsourcing of various RSC operations may result in gaining higher process efficiency and skilled knowledge, which in turn could reduce reverse logistics costs (i.e. economic value) and also create process knowhow (Fleischmann and Kuik, 2003). Several other forms of collaborative relationships can be noticed in RSCs to create multidimensional values, e.g. supplier relationship management is aimed at lowering supplier opportunity costs (Aitken and Harrison, 2013), while other coordinating mechanisms through information sharing (Jayaraman et al., 2008; Olorunniwo and Li, 2010; Son et al., 2015), joint problem-solving (Simpson, 2010), collaborative education and workplace training (Pal, 2017; Xie and Green, 2012), and dual IT and reverse logistics competency can ensure higher transparency, information integration, efficiency, environmental behaviour etc.

\subsection{Collaborative RSC relationships}

Inter-organizationally, value is created as a result of relational rent, i.e. through the transactions and exchanges between dyadic partners (Dyer and Singh, 1998, Lavie, 2006; Touboulic and Walker, 2015). Thus far, inter-organizational collaboration and relationships provide opportunity to create supernormal rent, hence profit, that could not otherwise be created by the organizations independently. Dyer and Singh (1998) define the key to developing such relational rent in dyadic relationships are idiosyncratic combination, exchange or investment in resources, assets, knowledge, and its effective governance in order to develop competitive advantage in the market. Sources or determinants of such relational rents are based upon: (i) creating relationship-specific physical and human assets, (ii) sharing of information and know-how to create inter-organizational learning, (iii) complementary resource endowments resulting in joint creation of indivisible assets, and (iv) effective governance and safeguarding instruments to reduce transaction costs, thus forming the core tenets of RT (Dyer and Singh, 1998; Lavie, 2006). RT has been fundamentally applied to study such dyadic relationships; in particular to examine strategic collaborations in various buyer-supplier contexts (e.g. Touboulic and Walker, 2015). Recent RSC studies have also referenced certain elements of RT to explore the relational or collaborative aspects of value creation in RSCs, e.g. relational asset generation (Chan, 2007; Simpson, 2010), information sharing (Li and Olorunniwo, 2008; Olorunniwo and Li, 2010; Son et al., 2015), knowledge codification (Aitken and Harrison, 2013), resource complementarities (Simpson, 2010), governance mechanism (Aitken and Harrison, 2013; Daugherty et al., 2003; Jack et al., 2010).

When it comes to relational assets specific to RSCs, Simpson (2010) has studied the role of firm's partnership with supplier and customers to resolve recycling problems by codeveloping packaging solutions, which was otherwise not evident in less-collaborating firms. Similarly Chan (2007) studied the manufacturer-supplier cooperation and its role in designing new returnable packaging in a cross-company team of engineers who worked together to familiarize with each other's processes. Retailer-supplier investments in developing RFID technologies for centralised warehousing, as studied by Jayaraman et al. (2008) similarly highlighted the role of relational asset-specific investments (in RFID tags), that benefitted in reducing uncertainties related to information accuracy on product status, location, and condition, and at the same time improved material acquisition dependability for the supplier.

Seamless information sharing is another requirement for instating dyadic relationships in RSCs. Both, Li and Olorunniwo (2008) and Olorunniwo and Li (2010) have indicated that information sharing leads to greater collaboration, which in turn improves reverse logistics performance. Such information sharing initially involves intense data exchange, to built-in 
higher trust, and firms may gradually escalate the relationship toward joint strategic processbuilding. Ultimately this may lead to higher supply chain visibility enabling better coordination, efficient operations, cost reduction, and customer service. A significant role in enhancing such information sharing in RSCs is played by advanced information technology (IT), as shown by Chan (2007). The paper highlighted the role IT in facilitating information exchange in cross-company teams to improve reverse logistic by reducing lead time and generating knowhow. Aitken and Harrison (2013) also showed how such enabling technologies can enhance value, by simplifying transactions by removing middlemen, and increasing "competence trust" particularly in terms of quality and service demanded by the focal firm. A critical requirement in such trusted relationship is knowledge codification (Aitken and Murray, 2010), that can develop and formalize knowledge sharing routines which both, enhances relationship commitment and reduces transaction-specific complexities. With standards being developed between the partners through such codification, more formalized reporting structure for information exchange regarding inventories, availability, prices, etc. can be pursued. However, often in such contexts value appropriation happens asymmetrically, and the partner having greater access to information also gets higher share of the jointly created "profit" (Cox, 1999; Lavie, 2006; Nyaga et al., 2013). Only Son et al. (2015) prescribe a solution through better revenue sharing model for incentivizing collectorremanufacturer knowledge and information sharing for capacity design.

RT further highlights the role of indivisible complementary resources in dyadic relationships, particularly specialized expertise and intangible assets, in order to generate relational rent (Dyer and Singh, 1998). In RSCs, Simpson (2010) highlighted the joint efforts in relationship-based recycling that firms took in order to identify both materials and potential markets. The study identifies such critical complementarities in the partnership, e.g. one of the firms developed a specialised technology for innovative recycling, while another firm employed a waste manager solely to manage the firm's wastes and identify external recycling opportunities. In doing so, these firms were able to jointly generate indivisible information on how to reduce the recycling barriers, reduce information asymmetry, aggregate need and increase innovation opportunities.

Finally, previous RSC studies (e.g. Jack et al., 2010) have highlighted role of governance mechanism as tool to safeguard transactions, in order to reduce risk of opportunism and ultimately strengthen value creation in RSC dyads. Beyond third-party enforced instruments, e.g. legislative restrictions and extended producer responsibility laws, whose presence largely differs across different countries and industries (see Erol et al., 2010; Jayaraman and Luo, 2007; Lau and Wang, 2009), other self-enforced formal contractual arrangements have been discussed to positively influence reverse logistics capabilities leading to cost savings and improved performance (Jack et al., 2010). On the other hand, a number of studies from the car industry's RSC showcase how such informal instruments such as trust is essential to create relationship commitment (Aitken and Harrison, 2013; Daugherty et al., 2003). For instance, Daugherty et al. (2003) investigated relationship-orientation through trust-relationship commitment in automotive aftermarket to reveal that higher trust and relationship commitment between the buyer-seller can reduce partner opportunism, and can enhance reverse logistics performance and customer relations for both partners. The role of (competence) trust development in RSCs is further highlighted in Aitken and Harrison (2013), in order to handle complex transactions, and can even influence the dyad's governance structure administered through regular meetings and information exchange instead of periodic meetings. 
Summing up, current RSC studies highlight the relevance of RT to multidimensional value creation. However it can be simultaneously concluded, that each of these prior studies are limited to investigation of a single source of relational value, with cases of similar type of dyadic relationship (mostly, buyer-seller or supplier-customer type). This limits the scope of understanding the value multi-dimensionality, and capturing the complexity due to which issues like asymmetry involvement, power imbalance, and opportunistic behaviour are inevitable in dyadic interactions (Nyaga et al., 2013), and are also inherent to RSC dyads to undermine value creation. In the light of this gap, this paper lays a well-grounded theoretical foundation (that of RT) in identifying the sources of these values, and how they are created in diverse dyads in RSC context.

\section{Methodology}

Given the relative dearth of theoretical underpinnings to study the phenomenon of multidimensional value created relationally in RSCs, the choice of conducting an explorative case study is pertinent in order to uncover specific areas for research and theory development (Ellram, 1996; Voss et al., 2002); here the research specificity is towards generating deeper understanding and elaboration of how multidimensional values are created through different $\mathrm{RSC}$ relationships. With RT as the $a$ priori theory (motivated above as the starting point) and choice of extreme cases from used clothing RSC, we adopt an abductive reasoning to simultaneously reconcile with contextual idiosyncrasies (Ketokivi and Choi, 2014; Kovács and Spens, 2005), as has been practiced in previous supply chain management research for theory elaboration (e.g. Ketokivi, 2006). Through an in-depth understanding of used clothing RSC cases constituted by members engaged in diverse dyadic relations and transactions, the paper thus extends the notion of relational value creation in RSC context. Beyond providing a detailed description to these highly complex, and relatively less-explored, dyadic relationships that creates multidimensional values between different RSC members, the research further explores the empirical context with more latitude and serendipity, to therefore challenge and elaborate the theory (Ketokivi and Choi, 2014). With a rich source of qualitative, empirical data used in this study, the appropriateness of a case study approach is further established (Ellram, 1996).

\subsection{Case selection and description}

As highlighted by Sandberg et al. (2018), the used clothing RSC is unique and complex due to a number of reasons: it includes diverse types of players with different value creation motives and incentives, it is influenced by different external factors, e.g. multiple countrylevel regulations and laws due to its global stretch, and also involves different types of relationships, e.g. cost-neutral, buyer-seller, donations. Also a number of different values (economic, environmental, image, information, and customer) are created in such RSCs (ibid). Such a used clothing RSC thus constitutes an information-rich context, full of extremes, that is valuable for an in-depth case study (Flyvbjerg, 2006), as it provides an appropriate ground to apply and elaborate a theory (Eisenhardt and Graebner, 2007). Within this context, theoretical sampling (Eisenhardt and Graebner, 2007) was used to select three cases (see Figure 1 below), each representing archetypical dyadic relationships embedded in the used clothing RSC. In line with the research purpose, the four sources of RT serve as the unit of analyses within each case to inquire how multidimensional values are created relationally in RSCs.

INSERT Figure 1. The three cases along used clothing RSC 
- Case 1: Take-back scheme involves globally operating commercial broker/sorter (B/S) and fashion retailer $(\mathrm{R})$. The $(\mathrm{R}) \mathrm{s}$ in this study organize take-back of used clothes, by offering strategic store locations for setting up of collection bins, which are then handed over to the collaborating for-profit $(\mathrm{B} / \mathrm{S})$ who takes the used clothes through the next reverse logistics stages, i.e. sorting and repurposing. The used clothes are not owned by the $(\mathrm{R}) \mathrm{s}$, and after collection these are despatched first to a country-level warehouse or split-point of the $(\mathrm{B} / \mathrm{S})$ before getting transported to their own sorting facility. One of the main aspects of this take-back scheme is a cost-neutral agreement [1], i.e. in case of loss incurred by the (R)s during take-back operation, $(B / S)$ would bear the additional cost while in case of a profit (R)s need to donate the amount for extending corporate social responsibility.

- Case 2: Charity-involved scheme represents the multi-sided dyadic relationships involving charity $(C)$, either with second-hand retailer $\left(2^{\text {nd }} R\right)$, broker/sorter $(B / S)$, or even fashion retailer (R). The (C)s undertake RSC operations, such as collection, (manual) pre-sorting, and resale of used clothes either to $\left(2^{\text {nd }} \mathrm{R}\right)$ or global $(\mathrm{B} / \mathrm{S})$. After collection via multiple channels (e.g. own stores, kerb-side) and pre-sorting, the (C)s sell the clothes to their partners $(B / S)$ or $\left(2^{\text {nd }} R\right)$, in both Europe and Asia, that totals to $10-15 \%$ of the used clothes in the global aftermarket. This case consolidates instances of different relational structures observed in charity-involved schemes between (C) and $(B / S)$ or $\left(2^{\text {nd }} R\right)$, such as that of trading subsidiary-based [2], reverse logistics outsourcing, and strategic alliance. In addition, collaboration between $(\mathrm{C})$ and $(\mathrm{R})$ for value-added redesign are also included. These (C)-(R) collaborations are pilot projects, but have gained prominence in the recent years.

- Case 3: Regulated trade scheme operates downstream in the used clothing RSC, and depicts the relationship between specialized sorting firm (SS), located in the low-cost developing countries, here India and their suppliers, i.e. the global (B/S). These (SS) buy the used clothes from the $(\mathrm{B} / \mathrm{S})$, to further sort, sometimes mutilate and recycle, and finally sell them in the competitive aftermarket, either to local trading firms and receivers in developing countries (e.g. in Africa), or as recycled yarns back to the (B/S). Governed typically by arm's-length transactions, these schemes are subjected to certain governmental restrictions (in India) exercised in the form of trade licenses [3].

Overall, these three cases constitute a multi-tiered supply chain-level case in used clothing industry, involving diverse members as shown in Table 1.

INSERT Table 1. Case study of multi-tiered, used clothing RSC

\subsection{Data Collection}

Three sources of data were used: interviews, site visits and documentation (Table 2). The main source of data was open-ended interviews, while the other two sources were used mainly to triangulate certain facts and interview interpretations. The data points were purposefully selected to be non-paired RSC members due to: (i) lack of considerable transparency in used clothing RSCs in terms of revealing names of dyad partners, (ii) challenges inherent to locating and reaching out to geographically dispersed dyads, and (iii) lack of interest of members in sharing information on specific relationships dyads, and instead talk in general. For instance, a paired case of ( $\left.2^{\text {nd }} \mathrm{R}\right)-(\mathrm{SS})$ relationship could not be included as those $\left(2^{\text {nd }} \mathrm{R}\right)$ in the study did not have specific buyer-seller relationship with the specialized sorters from the developing country authors had connection with. Thus 
convenience was a key criterion to develop three consolidated cases of different RSC dyads, by purposefully sampling the representatives (Patton, 2002), given constrains such as ease of access and sensitivity.

Insert Table 2. Data collection methods

Open-ended interviews. The empirical data is based on 17 interviews with two (R)s, two ( $2^{\text {nd }}$ $\mathrm{R}) \mathrm{s}$, three $(\mathrm{C}) \mathrm{s}$, two $(\mathrm{B} / \mathrm{S}) \mathrm{s}$, and four $(\mathrm{SS}) \mathrm{s}$. Because we were seeking the "stories" that the respondents had to tell about their dyadic relationships in general, our questions were openended queries (in line with the RT sources) focusing on e.g. RSC assets and resources, partnerships and collaboration, contracts, used for value creation in the dyads each member was involved with. Due to the use of non-paired units of observation constructing the data source for each case, we did not seek information related to any specific relationship with a partner, instead used the three case contexts (e.g. take-back scheme for Case 1) to guide the questions. The questions were devised in such a way that they could capture pieces of information on the RSC schemes, which was then analysed by the researchers in accordance to four sources of RT (as described in section 3.3). The interview questions consisted of two parts: the first part was aimed at seeking brief information about how and why the members are engaged with the used clothing RSC?, what are their main motives and reasons?, what are the key activities they engage with and what resources, assets etc. are involved/required?, who are their partners, suppliers and customers, and also competitors?, and what values do they create/what incentives they have through their engagement? These questions were further guided by some relevant keywords during the interview process, e.g. when asking about the key resources and assets, we specifically asked about their infrastructure, skillset, process knowhow for each engaged activity, e.g. collection, sorting, reprocessing. Further when asking about the values being created, we mentioned the five value types (economic, environmental, image, information and customer) to direct the responses. The second part of the interview included specific questions related to the key partnerships and collaboration each RSC member has mentioned, thus asking about how would they describe these relationship with their collaboration partners?, how do they interact in these partnerships/collaboration?, who brings what into the partnership/collaboration (e.g. assets, skills, resources, knowledge, ...)? Suitable keywords, e.g. information sharing, joint planning and value creation, governing rules and contracts, trust, etc. were used, where necessary, in order to prop the respondents through the interview process.

Respondents from each organization were selected based on their knowledge and experience related to the used clothing RSC. These were mainly the sustainability managers from the $(\mathrm{R}) \mathrm{s}$, operations manager dealing with reverse logistics from the $\left(2^{\text {nd }} \mathrm{R}\right) \mathrm{s},(\mathrm{C}) \mathrm{s}$ and $(\mathrm{B} / \mathrm{S}) \mathrm{s}$, and the owner-managing directors of the (SS)s - in short all of them were the most informed and relevant person related to the studied context. All the interviews were in English, digitally recorded and transcribed verbatim, which accounted to a total of $\sim 12$ hours of recording. Each interview lasted between 30 minutes and one hour. Recording the interviews was not an issue for the respondents as long as the anonymity was maintained.

Site visits. Multiple site observations were made through visit to the stores, pre-sorting and sorting facilities of the members. The visits allowed the researchers to get an understanding of the firms' RSC activities, and also several key relationships salient to product and information flows in RSCs. The main aim was to initiate informal conversations with different personnel, 
regarding how they engage to demands from partners, how work routines are followed etc. For instance, the sorting facility personnel at $(\mathrm{B} / \mathrm{S})$ were asked about key requirements at the sorting floor when they are involved in take-back schemes, the store personnel at (R) were asked about the customers' requirement when depositing used clothes, while the sorters in (SS) were asked about the operational requirements when their company strives for a competitive export-import. Notes were taken during the visits and were later used to verify the information availed through other data sources. Generally, each visit lasted between 30 minutes and 3 hours, depending upon the scale of operation and other practical constraints at the organization, and was conducted in most cases following the interview with the organization.

Documentation. Additional documents concerning RSC relationships and activities were collected. Type of these documents is listed in Table 2. In particular, there were a lot of online materials (e.g. posts, news and videos) available on Cases 1 and 2 which clearly highlighted the RSC activities that the members are jointly engaged with and how they benefit in terms of value creation. Communication activities via websites and other media coverages were retrieved where necessary.

\subsection{Data Analysis}

Interpretive data analysis was conducted in two stages, within-case and comparative-case, as also recommended by Miles and Huberman (1994). Firstly, in the within-case analysis descriptive write-ups of each case were constructed separately (Barratt et al., 2011), by narrating the salient characteristics of the observed dyadic relationships among the involved RSC members, along the four sources of relational value prescribed in Dyer and Singh (1998). During the process, interview quotes and extracts from other data sources were used for both, emphasizing and linking analysis to data (Fawcett et al., 2014), thus enriching the case descriptions. This was followed by comparative case analysis to compare and contrast the relational characteristics across the three RSC cases, and to highlight any emerging pattern at the supply chain level, which was reflected in the propositions. To reduce any researchers' biasness in the process of locating identifiable patterns, as advised in Barratt et al. (2011), $a$ priori constructs (here RT sources) were used for data fragmentation and while looking for evidences.

Following interview transcription, a set of formalized steps of codification, writing, reflecting and sorting of data were rigorously carried out to present the research (Miles and Huberman, 1994). Firstly, tabulated spreadsheets were constructed per case, with columns listing the data sources (including field note observations and collected archival documents) and rows listing the fours RT sources. Then the transcripts and notes were tagged using suitable colour codes per each RT source, to simultaneously populate the spreadsheet. This helped in constructing the within-case "stories" in accordance to RT to maintain the "chain of evidence" (Barratt et al., 2011; Ellram, 1996), between data, analysis and construct (here, four RT sources). Finally these case-wise spreadsheets were combined and were confronted against theory leading to the development of propositions along each RT source, as presented in section 5.

\subsection{Research Quality}

A common way to ensure robustness and legitimacy of a case study research is by ensuring validity and reliability (Ellram, 1996; Voss et al., 2002). Internal validity has in this research been ensured at the data analysis stage through the separation of the key constructs (in accordance with the four RT sources) and establishing their theoretical relationships to the outcome, i.e. multidimensional values (as shown in Table 3). Further the structured procedure 
followed for both within- and cross- case analyses to, code, write, reflect on and sort the data, as mentioned in section 3.3, ensure validity of the data categories, and support established patterns. In order to establish external validity for generalizability of the research results, stating the replication logic and verifying the pattern are crucial (Ellram, 1996). In order to ensure this, three case studies (from used clothing RSC) are used and contrasted. By using RT lenses, the characteristics of these dyads are compared along the supply chain to established "theoretical patterns", e.g. between degree of opportunism in the relationship and ways of creating value. The results, i.e. the developed propositions are thus largely applicable to other used clothing RSC cases spanning Global North-South, and furthermore to similar industrial RSCs too. Construct validity is largely established in this study by using multiple sources of evidence - interviews, site visits and documentation - for data collection (see section 3.2). Triangulation of the data was further ensured during the data analysis stage by using structured datasheets to not only combine and present the data, but also to construct the within-case "stories" in accordance to RT to maintain the "chain of evidence". Finally, reliability is addressed by ensuring repeatability of the case experiment by using an openended interview guide derived from the purpose and RT sources, and during the research process by storing all data collected as recorded interviews, transcripts, and field notes taken during site visits.

\section{Consolidated within-case analysis}

In this section, each within-case analysis briefly presents the dyad relationship of the members participating in the scheme, described along the RT sources.

\subsection{Case 1. Take-back scheme}

The take-back scheme collaboratively arranges specific assets, such that the in-store collection bins owned and set-up by the $(\mathrm{B} / \mathrm{S})$ are installed at convenient and strategic store locations offered by the (R)s to ensure better quality and high volume of collection. In general, the quality of the material is also better when collected in-store compared to those in charity-installed bins. These collection bins are cardboard boxes specifically designed by the $(\mathrm{B} / \mathrm{S})$ for easy in-store installation. This enable both $(\mathrm{R}) \mathrm{s}$ to improve their consumer's experience while donating used clothes, which may in turn facilitate higher collection volume. To ensure this, $(\mathrm{R}) \mathrm{s}$ develop clear communication plans conveying the long-term vision of the take-back scheme. Such plans in addition allow receiving vital information on consumer perception and feedback towards the take-back scheme. One of the (R) stated how they think such consumer feedback at the stores (or online) provides an indication towards favouring simple and convenient in-store systems over other options, such as donating via charities or thrift shops. Both (R)s perceived that investments made to specifically improve the performance (i.e. customer's ease of donation) would clearly scale-up the take-back potential, and will generate considerably lesser environmental footprints through reuse. Both $(R) s$ were thus willing to make further investments, e.g. towards campaigns and publicity via social media, or by issuing discount vouchers, that could encourage more deposits. Particularly, the discount vouchers are issued to the consumers each time used clothes are deposited via the take-back scheme, and the (R)s see this to positively influence the in-store collection volume and adopt it across more stores. Since launch one of them has thus established the scheme in nearly 21 out of 65 of its stores in Europe within one year.

In the take-back schemes, the presence of the $(\mathrm{B} / \mathrm{S})$ was also a source of information transparency. Both the $(\mathrm{R}) \mathrm{s}$ felt that by collaborating with the commercial members like $(\mathrm{B} / \mathrm{S})$ provide them higher information, as one of them stated " [...] we have always communicated 
to be commercial in our collaboration (with $B / S$ ) [...]. (It is the) commercial attitude what we like, as we know where and how the used clothes end up (compared to if we partner with charities)". Such transparency was adjudged to be important when communicated through social media to gain trust of the end consumers, which in turn generated better responsibility image and higher collection volumes for both $(\mathrm{R}) \mathrm{s}$. For the $(\mathrm{B} / \mathrm{S})$ the consumer information served as an essential source of understanding of the value of the "resources" that are lying in consumers' wardrobe with potential for reintegration into the value chain of the partnering (R)s. To complement this information, the $(\mathrm{B} / \mathrm{S})$ has developed a common knowledge platform to share its knowhow and expertise of close-loop processes with the (R)s. One respondent from a $(\mathrm{B} / \mathrm{S})$ stated, "for us it is absolutely vital that the retail partner knows the possibilities in their production chain because only then we can start working together with their producers and settle those new routines and procedures in the facilities." Another respondent stated, "financially we are looking at a circular economic model and of course every stakeholder in that value chain has to benefit. Once you sell the fibre the producer can buy those at cheaper costs than they would for virgin material". On one occasion this helped one of the (R)s in developing a denim collection out of recycled fibres from $(B / S)$ and, with this support, reintegrate the material back into the value chain.

Further complementary skills and resources of $(\mathrm{B} / \mathrm{S})$ and $(\mathrm{R}) \mathrm{s}$ largely determine the success of the take-back scheme. The $(\mathrm{B} / \mathrm{S})$ possess detailed knowledge and skills related to grading and sorting large volume of used clothes. Such sorting can go upto handling over 350 different parameters for categorizing the collected items, e.g. on the basis of quality, type, material composition, and even brand to fetch higher price points in the global market. $(\mathrm{B} / \mathrm{S})$ mentioned that in a recent project, one of its partner (R) bought back its own brand of sorted clothes to develop a redesigned collection and seek other circular business opportunities, like selling "green" collection made out of recycled materials. The project, even though a pilot, further offered (R) the possibility to demonstrate extended responsibility, through collaboration with $(\mathrm{B} / \mathrm{S})$ who managed the value-adding processes from sorting to recycling and further till its reintegration into (R)'s production chain. On the other hand, $(\mathrm{R})$ utilized its in-store collection system together with the third-party logistics infrastructure to ensure $(B / S)$ receives the used clothes in large volumes, at its national pick-up point on a regular basis. This was achieved by integrating the forward and reverse logistics service providers' capacity, for delivering the new clothes to store, and also to pick-up the used clothes in filled collection bins from the stores and deliver to $(\mathrm{B} / \mathrm{S})$ 's warehouse. This kept the distribution costs low for $(\mathrm{R})$, while for $(\mathrm{B} / \mathrm{S})$ this reduced their collection challenges as faced by the rival charities.

Governance of the take-back scheme is based upon a cost-neutral financial agreement issued by $(B / S)$, such that the $(R) s$ earn revenue from the sale of the used clothes to the $(B / S)$, paid per kilogram $(\mathrm{kg})$ of collected volume, and in turn bear costs related to collection and distribution to $(\mathrm{B} / \mathrm{S})$ 's warehouse. $(\mathrm{B} / \mathrm{S})$ bears the cost differential in case of any deficit, i.e. if the earning from the sales of the used clothes is lower than the incurred costs by $(R)$ s. In case of profit by $(\mathrm{R}) \mathrm{s}$, it is required to be donated for philanthropic activities. One $(\mathrm{R})$ respondent indicated that their profits were used for extending corporate social responsibility (CSR) programs, e.g. training and employee welfare at one of its supplier factory in Dhaka. No legal obligation underpin such financial agreements; and in fact beyond the goodwill trust the cost neutrality safeguards both (R)s from incurring losses at the initial stages of joining the takeback scheme, which could happen inevitably in the absence of the cost-neutral contracts. Such safeguards provided more incentive to the (R)s to scale-up the take-back scheme, as both started offering discount vouchers to its consumers. Upscaling the take-back scheme did not 
only increase the scope for profit-making, but also improved the green image based on showcasing the sustainability impacts of the scheme. $(\mathrm{B} / \mathrm{S})$ largely vouch on such sustainability image of its retail partners; as it was pointed out that implementation of such new schemes need " $a$ whole lot of communication, [...] so we urge our retail partners to start communicating to their customers and give them an understanding of the value and the resources that they have lying around at home and can possibly deposit". This further ensures higher economic value for $(\mathrm{B} / \mathrm{S})$ through upscaled volume.

\subsection{Case 2. Charity-involved scheme}

Different charity-involved dyads constitute this scheme together with, second-hand retailer $\left(2^{\text {nd }} \mathrm{R}\right)$, broker/sorter $(\mathrm{B} / \mathrm{S})$, and even fashion retailer $(\mathrm{R})$. One $(\mathrm{C})$ maintains a long-term buyer-seller relationship via its trading subsidiary, so that it can continuously gather better understanding of the local needs in each market from its partnering $(B / S) s$ and $\left(2^{\text {nd }} R\right)$. Such cooperation proved to be a source of good quality branded items for the $\left(2^{\text {nd }} \mathrm{R}\right)$ in making right assortment plans, as was stated by a respondent from (C), "they did not have reputed brand's jeans, so for them it's a complement (to their assortment)". Further the trading subsidiary also ensured lower transaction risks by establishing business-specific codes of conduct in the used clothing exports. Such codes written specifically for each partnering $(\mathrm{B} / \mathrm{S})$ created compliance standards for worker rights and conditions, and also guaranteed competitive price points for (C) in the market. The respondent highlighted that in such a subsidiary-mediated model the price of used clothes can be sometimes doubled, going upto 0,4 Euros per kg against 0,2 Euros as normally fetched by charities operating directly in the global aftermarket. In another dyad, one (C) developed a strategic alliance with a globally operating $(\mathrm{B} / \mathrm{S})$, which invested in establishing an automatic pilot sorting plant in Sweden with the objective of meeting the supply-demand needs of used clothes more locally. For (C) it was important to cut down the unnecessary transportation cost related to sending the locally collected materials all the way to $(\mathrm{B} / \mathrm{S})$ 's current sorting plant in Germany. On the other hand the prospects of such an alliance motivated $(\mathrm{B} / \mathrm{S})$ to improve their sorting effectiveness (beyond $80 \%$ reached in the German sorting facility) by adapting more to the local market needs. Thus the prospect made (C) invest and, with some support from the Swedish government, establish a training program to educate sorters for the new plant of $(B / S)$.

In order to meet the alliance objective, the partners further launched a program through which the sorters could be trained on how to manage dynamic stock-keeping parameters suited to the market needs. Such training extensively required sharing $(B / S)$ 's knowledge of commercial sorting on how to identify sorting parameters and different fractions, check the quality of the incoming materials, etc. and at the same time (C)'s inputs on how to constantly spot the local market needs, seasonality and trends. Developing such a program meant that, for instance, the trained sorters can now categorize used clothes more dynamically, e.g. a jacket could be defined as a seasonal/vintage/branded, based on market requirement, using simple on-floor charts and sorting criteria. On another occasion, such training was developed internally by one of the (C)s in order to take a formalized approach towards performing certain creative and tacit remanufacturing operations (disassembly and reassembly) in a more repetitive way. To aid this routinization of the processes, product development diagrams and construction steps were created by the designers at (C)'s remanufacturing facility that served as a good material to codify this skill. A respondent from (C) reflected, "[...] there are a lot of second-hand shops, many small companies or charities who do not know how to set the price. We always say that we have great set up, so we know how much to price." Such codified know-how seemed essential to set extremely high price points of (C)'s remanufactured products when selling to its retail buyers. 
In some of these dyad examples, complementary partner skills and resources particularly play an important role to create relational value. As indicated by a respondent from $\left(2^{\text {nd }} R\right)$, many years of establishment and practices has made its partner $(\mathrm{C})$ possess necessary competence and product-related knowhow required to make the first (manual) sorting process quick and efficient, i.e. how to minimize handling time during sorting by knowing exactly the grading check-points, e.g. labels or commonly stained places like collars. One (C) respondent said, "we are always testing different ways (colour maps, standard price segments, categories) on how to do more effectively, better, economically [...]. We want special employees be able to stand in many different stations [...] It comes out to spread knowledge so everyone can work pretty much at all station." This benefitted both the partner $(\mathrm{B} / \mathrm{S})$ and $\left(2^{\text {nd }} \mathrm{R}\right) ;(\mathrm{B} / \mathrm{S})$ indicated how they can easily fetch a very competitive price (upto 0,5 Euros $/ \mathrm{kg}$ ) when reselling them in the developing markets, while for the (2nd R) this meant access to export quality second-hand clothes. Further the volumes were almost 10-15 times than collected by individual retailers. In addition, for $(\mathrm{B} / \mathrm{S})$ this is also crucial to lower the collection and inbound transportation costs. One of the $(\mathrm{B} / \mathrm{S})$ respondents explained, "we do not pay for containers placement but we pay for the job to collect clothes [...] for each kilogram they collect for us. It depends upon, how much job they have for collection, how far they have to drive. Textiles boxes are ours, we find the company that can do collection for us". In another example, the $(\mathrm{C})$ and $(\mathrm{B} / \mathrm{S})$ relationship extended beyond that of traditional buyer-seller, into that of reverse logistics outsourcing by (C) to operate more efficiently in global value chain. (C) ran its large collection network and value-added sorting of used clothes, while the global transportation network of $(\mathrm{B} / \mathrm{S})$ efficiently distributed the used clothes to the destination markets (in Asia and Africa). Thus while short distance, intra-country transportation was handled by (C) with support from local municipalities, $(\mathrm{B} / \mathrm{S})$ took control over the global distribution. Further, in a couple of collaborative pilot projects between $(\mathrm{C})$ and $(\mathrm{R})$, such resource complementary could also be noticed. One (R) respondent mentioned, "in-store collection of used clothes offer better quality due to higher monitoring at the collection points as every bag from the customer is opened to check the contents before they are deposited". In addition, the (C)s also receive a lot of leftover stock from the (R)s as donation, which improves (R)s' image by undertaking environmental and social responsibilities, "the charities being the largest processor of used clothes generate a lot of impact in the eyes of the consumers through their activities, thus creating socially responsible image. We are new in showcasing our responsibility [...] should vouch upon more collaboration". Similarly on another occasion, in a redesign project, (R) vouched upon its partnership with (C) to showcase the benefits of the collaboration in terms of its environment friendliness in order to create considerable "buzz" among its consumers.

To safeguard the typical buyer-seller relationships discussed above, long-term contracts were issued in order to reduce the transaction risk related to, e.g. managing logistics of waste being sent in bales, delayed payments, etc. thus ensuring profits and traceability. These transactionspecific contracts, were further supported through business-specific codes of conduct devised by the $(\mathrm{C}) \mathrm{s}$ in order to hedge any risk in the alliance that may arise due to illegal or unethical issues, that are quite common in such cross-border trading practices. Despite the strictness of these codes in enforcing control over the operations, interestingly $(B / S)$ and $\left(2^{\text {nd }} R\right)$ did not see these codes as a burden but rather as a tool to enhance the RSC performance, particularly because of the openness of the contracts that offset any inconvenience that the codes might bring. It was also indicated that the possession of a particular $90 \mathrm{~s}$ account (issued by the Swedish Fundraising Control) by the (C)s guaranteed meeting a strict set of demands for collection and fundraising activities thus building honesty and trust in the relationship, as both 
$(\mathrm{B} / \mathrm{S})$ and $\left(2^{\text {nd }} \mathrm{R}\right)$ considered this to be essential in keeping a high standard in the business transactions.

\subsection{Case 3. Regulated trade scheme}

The (SS)s operate in special economic zone (SEZ) in a highly regulated trading environment set by the Indian government. Working in the SEZ allows the (SS)s to undertake operations like sorting and mechanical recycling, with the embargo of exporting the entire volume after value addition. Hence the products are not allowed to enter the local market as used clothes. The government has restricted the number of firms that can enter the trade by issuing limited licenses acquiring which involves lengthy and expensive procedures for the (SS)s. Apart from the monopolistic control that these (SS)s enjoy over the used clothing trade due to the licenses, from the relationship point of view this adds legitimacy to the export-import with the partnering $(\mathrm{B} / \mathrm{S}) \mathrm{s}$. One of the (SS) respondents mentioned, "without a license the companies can only act as a sub-contractor (and not as a value-added intermediary), which is of concern to those global (B/S) who are buying back recycled yarns (from us)'”. Further these licenses to operate in SEZ exempts both the members from paying any export-import duty or custom fees, which result in lowering the cost of the final product. In particular, the SEZ is located near the port of Kandla (by the west coast of India) which reduces the inland transportation and freight costs incurred by $(\mathrm{B} / \mathrm{S})$ compared to if they had to send the material to the inland city of Panipat, which is the largest mechanical recycling hub but only offers poor quality items, like rags and shoddy. In order to sustain this cost advantage, one of the (SS) also acquired complementary recycling skills to integrate vertically, i.e. segregate used clothes, mutilate them and then produce finer quality mechanically recycled yarns (by capitalizing on the transportation cost advantage of its partner), thus fetching a price almost 12-15 times more than the low quality items produced in Panipat.

Even though these regulated trade schemes generally operate with a fierce profit maximization motive of both members, (SS)s always aim at more alignment of their incentives to produce good quality and high volume of exportable materials (including recycled yarns). It was intimated by a (SS) respondent that nearly $40-50 \%$ of the imported materials (the best quality) are currently re-exported, thus the quality of the incoming material from the $(\mathrm{B} / \mathrm{S})$ is a crucial decider. One $(\mathrm{SS})$ owner added, "we face problem due to quality. We pay for good quality but sometimes we receive low quality mix rags. [...] if we do not maintain good relationship then how can we get good value products? [...] if we need high quality we need to speak to the broker constantly [...] but not negotiate". Such personal contacts with the $(\mathrm{B} / \mathrm{S})$, and often during their visits to the SEZs, ensured more information transparency about the source and quality of the imported materials, "we get good product (from the importer) because we know from where they are collecting goods". It is important for (SS) to improve the level of supplier relationship through such informal interactions in order to improve profits.

In order to ensure transparency in these dyads, $(\mathrm{B} / \mathrm{S})$ 's information-rich position as an intermediary in the RSC is crucial. Owing to their position, both the $(\mathrm{B} / \mathrm{S}) \mathrm{s}$ are able to leverage upon their sorting capabilities and complete knowledge of the processes and information related to product, source and destination market to ensure a smooth flow of material to the (SS)s. By handling the complex categorization of a large variety of used clothes - in terms of their residual value, type of fabric blends, and quality - into standard sizes of imported bales, $(\mathrm{B} / \mathrm{S}) \mathrm{s}$ are able to bargain a good deal with the $(\mathrm{SS})$. One of the $(\mathrm{B} / \mathrm{S})$ respondents added "we have special people who go to the sorting plant and educates on how to [...] categorize items more systematically, [...] be faster and efficient to reduce cost. This 
way we can be more efficient on the sorting job. Also we are training (them). This creates praxis". For the (SS)s, such knowledge and procurement of high quality sorted material sufficed confidence in the relationship thus reducing the efforts and cost to search new partners; however some (SS)s indicated how this could be risky when their partner (B/S) start exploiting their information-rich position for better bargains. Complementary to the knowledge accumulated by $(\mathrm{B} / \mathrm{S})$, the specialized skills and knowledge of the $(\mathrm{SS}) \mathrm{s}$ are equally important to segregate the used clothes, for example, into special rags (jeans rags, sweater rags or t-shirt rags) that are of higher price points compared to mixed rags. Such tacit knowledge is accumulated and passed over generations due to many years of practice and family ownership, which has resulted in developing a very cost-efficient management and training procedure.

In these dyads, by ensuring high material quality and delivery regularity consistently at low cost, trusted relationship was built to settle competitive purchasing negotiations. One of the (SS) owners mentioned that out of 14 companies in the SEZ, only 4 or 5 have such good relationship with their partnering $(\mathrm{B} / \mathrm{S})$ and buyers. "The main problem is percentage of different fabric in the imported container. Once, even though we have paid for a higher quality we received low quality mixed rags. [...] we immediately contacted the supplier and asked for reducing price. It is important to maintain good relationship to get good raw materials and vice versa". Such trust building sometimes extends into a very personal level interaction, as mentioned above; one of the owners informed that, "if someone comes to visit [...] we definitely get in touch with them, and take care. This is essential for our own brand image." However, on some occasions the partner $(\mathrm{B} / \mathrm{S})$ tried to exploit the strategic, information-rich position (due to their access to high-quality, sorted material) in order to make stringent bargains regarding price points. One of the (SS)s mentioned that in order to circumvent such situations they chose to directly deal with the second-hand retailers in Europe. Few respondents from (SS)s stated, "earlier we were importing through broker only. Now we have developed relationship with two-three second-hand retail suppliers who deliver on regular basis. We keep on searching for new supplier bypassing the middle men. [...] we have developed sufficient contact by searching on internet or by writing to them. We have also got registered at many more places". However this resulted in increased search cost for (SS).

\section{Comparative case analysis and propositions}

In order to reveal how multidimensional values are created through different reverse supply chain relationships, Table 3 presents a comparison of three used clothing cases that span over a complex and globally distributed RSC, along the four sources of RT. By drawing the lens of RT, the similarities and differences observed between the upstream and downstream stages of the RSC shown in Figure 1, reveal different patterns for value creation as the nature and characteristics of these relationships differ at the reverse supply chain level. Following the abductive nature of this research, these patterns are further presented in the form of propositions underpinning RSC relationship characteristics, each in accordance to one source of relational value.

INSERT Table 3. Summary of three cases

\subsection{Investment symmetry and opportunism in RSC relation-specific assets}


In all three cases, the dyadic relationships originate due to different levels of involvement and contribution, which further result in creating multidimensional values (economic, information, image, environmental and customer), as shown in Table 3. Such involvement by the dyad partners in terms of amplitude of efforts that is put into the relationship is observed to be asymmetric in nature, thus adjudging the partner's role. We refer to those who invest the larger share in terms of asset and resources for deploying the relationship as the "developer" (though not necessarily the stronger one in terms of power), while a "supporter" who invests the "smaller" share and do not drive the dyad scheme (though not necessarily the weaker one). Further, what is noticeable across the cases in the RSC is that the asymmetry in engagement is substantially higher downstream compared to upstream.

Downstream in the RSC (in Case 3), the supporter $(\mathrm{B} / \mathrm{S}) \mathrm{s}$ take a very opportunistic role, as with minimal investment into the regulated trade scheme they gain considerable value from the arm's length relationship, in terms of economic benefits and access to recycled materials. On the other hand the developer constantly invests, as in our study the (SS)s do, by getting trade licenses and thus adding locational advantages and legitimacy to the trade. By doing so, (SS)s generate incentives for the "opportunistic" (B/S) in realizing the long-term prospects of developing high-quality recycled yarns, hence become more transparent to (SS). Such commitment from $(\mathrm{B} / \mathrm{S})$ can align the relational values for both partners, together striving towards improving the quality of recycled materials. In the other two cases (towards the upstream RSC), there appears to be higher degrees of symmetry in the involvement (amount of resource engaged) by both partners. In Case 2, we can observe that the relationships include higher involvement from the supporters, $(\mathrm{B} / \mathrm{S})$ in trading subsidiary-based scheme and (C) in strategic alliance, as compared to Case 3, as they constantly gather local market knowledge to specifically improve the demand-supply alignment in these dyads. Such demand-supply alignment is crucial for improving economic value for both partners. For instance, in the $(\mathrm{C})-(\mathrm{B} / \mathrm{S})$ strategic alliance this resulted in reducing transportation costs to the level where $(\mathrm{C})$ can invest in the training program and improve $(\mathrm{B} / \mathrm{S})$ 's sorting effectiveness. Finally in Case 1, the investment in relation-specific asset is most symbiotic, as the partners together strive to maximize the total pay-off, i.e. improve the scale of the scheme. It is evident that $(\mathrm{B} / \mathrm{S})$ 's investment in the increasing the simplicity and convenience of the take-back system, was backed by (R)'s investment in various communication campaigns to incentivize the customer and receive feedback. Based on this analysis, we propose that:

Proposition 1: As the nature of RSC relationship changes from opportunistic (at downstream) to symbiotic (at upstream), relational asset is developed through more symmetric contribution (in amount of effort or investment) to create multidimensional values.

\subsection{Effect of nature of RSC relationship on knowledge sharing routines}

In terms of knowledge sharing in RSCs, Table 3 reveals how exchange mechanisms differ when the RSC relationship is more opportunistic (in Case 3) compared to being symbiotic in nature (in Case 1). It is observed that when the relation is opportunistic, i.e. the supporter's contribution proportion in the relational asset is the least; the developer often relies on informal relationships to extract more information. For instance, we observed that the (SS) relied on personal contacts with $(\mathrm{B} / \mathrm{S})$ as a way to develop social interaction (e.g. as hosts taking care of $(\mathrm{B} / \mathrm{S})$ during their visits), as a way to gather more information on the source and quality of the imported material. It was clear that such interaction to extract more information would not only appropriate more relational value for (SS) but might eventually lead to better alignment of both partners' incentives to produce good quality and high volume 
of recycled materials, thus initiating more reciprocation. In fact it can be deduced that such reciprocation is crucial for more alignment in RSC relationship, and for initiating joint efforts for knowledge sharing. Such joint knowledge creation and sharing is revealed in Case 2's (C)$(\mathrm{B} / \mathrm{S})$ dyad, where the partners align to co-create training procedures for sorting used clothes, through combination and integration of their respective knowledge of market requirements and process parameters - to simply routinize their tacit skills. Upstream in the RSC, i.e. in Case 1 where the involvement is more symbiotic, the information sharing is done more seamlessly. For instance, as $(\mathrm{R})$ gained information from $(\mathrm{B} / \mathrm{S})$ related to where and how the used clothes are destined, it was appropriately communicated to the end consumers to build up trust and receive consumer feedback. This information, in turn, is essential for $(\mathrm{B} / \mathrm{S})$ to evaluate the market opportunities and future potential of the take-back schemes. Thus as the partners began reciprocally sharing information, a seamless platform was developed based on this routine of knowledge exchange among all stakeholders - (B/S), $(\mathrm{R})$ and its suppliers - so that they can together strive towards an effective circular economy in textiles. We propose that:

Proposition 2a: As the nature of relationship changes from opportunistic to symbiotic along the RSC, knowledge sharing becomes more seamless (and routinized) to create multidimensional values.

Thus far, our discussion has focused on the type of knowledge sharing/exchange in RSCs. However, when it comes to the degree of effort in developing such exchanges, Case 2 reveals that most effort is taken in the RSC to create formal routines, either through training programs or standard codification documents, at the time of aligning the dyad partners' involvement. For instance, large investment was made in establishing such routines in the $(C)-(B / S)$ strategic alliance, for creating the training modules and sorting parameters for the sorters to educate them on market-driven dynamic sorting that was beneficial for both the partners. In contrast, in (C)-(R) dyad similar practices to codify the remanufacturing skills developed solely by $(\mathrm{C})$ were exploited in creating more bargaining opportunity, as it was a way to fetch higher prices from the retail buyers. Thus Case 2 revealed that as the dyad partners take the most effort through knowledge codification and integration for aligning incentives for relational commitment, it simultaneously opens up stronger bargaining opportunities if this knowledge or skills are accrued disproportionately by the partners. However, once the knowledge sharing routines are formed, and the incentives are already aligned, then the RSC relationship becomes more transparent. Therefore, we propose that:

Proposition 2b: Most effort to routinize knowledge sharing in RSC relationships is required for aligning the partners' incentives but it may enhance the bargaining opportunities too, if routines are not created jointly.

\subsection{Intangible asset commitment in RSC relationships}

In the RSC both upstream and downstream, complementary resource committed by dyadic partners particularly plays an important role in relational value creation, as was evident in all three cases. Table 3 reveals that common to the cases was how distinctive physical assets of the dyad partners were combined and complemented, irrespective of the nature of relationship, i.e. opportunistic or symbiotic, at all RSC stages. For instance, in Cases 1 and 3, the dyad developer's, i.e. (B/S) and (SS) respectively, capability to contribute with specialized sorting operations was valuable for the partnering supporters to meet their specific demand 
for circular material supplies. Equally important for value creation in these schemes was commitment of the supporter's infrastructural support, such as in-store collection system of $(\mathrm{R})$ in Case 1 to solve the "first-mile" handling challenges for $(\mathrm{B} / \mathrm{S})$. Similarly, Case 2 also revealed deployment and combination of a variety of such complementary physical assets of both the partners along the value recovery processes in order to establish sorting plants, logistics network, or collection channels, jointly.

In addition, all the cases revealed the criticality of specialized expertise or intangible assets for the relationships. In Case 1, (B/S)'s process knowledge and value chain management skills from sorting till circular material supply not only resulted in its information-rich positioning, but also benefitted partnering (R) in extending their responsibility image, and vice versa. Similarly, in Case 2's (C)-(R) dyad, (C)'s reputation and social responsibility image impacted (R)'s customer value. In another dyad, (C)'s sorting knowhow fetched competitive price points and good material supply for both $(B / S)$ and $\left(2^{\text {nd }} R\right)$. However in Case 3 where the relationship was highly opportunistic, combination of intangible assets by the partners, e.g. information-rich positioning or tacit process skills even though was beneficial to generate high-quality recycled yarns, largely resulted in originating antagonistic bargaining between the partners. Therefore, we propose that:

Proposition 3: In relationships across all RSC stages, intangible assets (e.g. reputation, skills or information-rich position within network) supplement physical asset complementarities to create multidimensional values however this may also result in higher bargaining power when opportunism is high.

\subsection{Additional safeguards for RSC governance and risk reduction}

All the three cases show the importance of trust building between dyad partners. In fact, trust building seemed to be the rudimentary requirement in relationships at all stages of used clothing RSC, i.e. from upstream to downstream, for various reasons, such as for safeguarding (R)'s participation in take-back scheme through $(\mathrm{B} / \mathrm{S})$ 's goodwill (in Case 1), for ensuring profits and traceability in the business through transaction-specific contracts (in Case 2), or for achieving high material and delivery service quality at low cost for both $(\mathrm{B} / \mathrm{S})$ and (SS) thus by relying upon competence (in Case 3). However, in addition to trust building other more prominent governance instruments were also observed to be utilized in RSCs, owing to their influence in reducing transaction or negotiation risks and related costs. For instance in Case 3, where the relationship was highly opportunistic in nature, (SS) relied on using informal ways, e.g. through personal contacts and social interaction, to increase their negotiation power and thus safeguard themselves from (B/S)'s strong bargains. Those (SS)s which did not develop such personal connections to extract information or negotiate, and build trust with $(\mathrm{B} / \mathrm{S})$, faced with the adversity where they were forced to develop direct links with upstream charities resulting in higher search costs. In Case 2 similar safeguards were operational, only that these instruments were codes of conduct (more formal instrument) enforced by (C)s. Typically these codes of conduct were stringent to meet standards for workers conditions at $(\mathrm{B} / \mathrm{S})$ and $\left(2^{\text {nd }} \mathrm{R}\right)$, but together with open transaction-specific contracts they hedged transaction risks that arose due to poor material quality or delayed payments. Thus instead of creating an acrimonious relationship (due to stringent requirements) these codes of conduct were instrumental in generating higher trust and traceability, and were considered important for incentive alignment. Such formal self-enforcing safeguards are also observed in Case 1 in the form of cost-neutral agreements which provided a "safety net" to (R) from incurring loss at the initial stage of participation in the take-back scheme, and thus 
prevent them from exiting quickly. Thus the self-enforcing financial agreements embedded goodwill trust between $(\mathrm{R})$ and $(\mathrm{B} / \mathrm{S})$. Therefore, we propose that:

Proposition 4: Beyond trust building additional safeguards are required in all RSC relationships - that shifts from informal relations to formal transaction-specific controls or financial incentives as the relationship shift from being opportunistic to symbiotic in nature, in order to reduce transaction-related risks.

We summarize the propositions 1-4 depicting the differences in relationship characteristics and sources of multidimensional value along the RSC, in Figure 2. Drawing the RT lens, these propositions uncover how the RSC relationships differ in terms of investment symmetry in relation-specific assets, knowledge or information sharing routines, intangible resource complementarities, and used of governance/safeguarding instruments, as we move from upstream to downstream.

INSERT Figure 2. Differences in relational value creation mechanism along RSC

\section{Discussion and Conclusions}

Proposition 1 refers to the relative difference in investment/effort required to develop relationspecific asset between the dyad partners, which originates different natures of relationship (opportunistic vs. symbiotic). This proposition extends the RT of Dyer and Singh (1998) which considers that rent through relation-specific assets depends on the volume of investment (and inter-firm exchanges), and that the value appropriated will be higher for the partner bringing higher (critical) resources - by highlighting that the proportion of investment made is crucial too in order to determine the RSC partners' roles (as either a developer or a supporter). Such roles in relation-specific asset development when taken into consideration along with the existence of power asymmetry (Cox, 1999; Nyaga et al., 2013) explains opportunism in RSC more explicitly in terms of natures of relationship that the previous studies (e.g. Chan, 2007; Sandberg et al., 2018; Simpson, 2010) do not address. The evidences reveal that in the downstream RSC (where the relationship is arm's-length), disproportionate effort (or investment) in relational-asset development results in higher opportunism, particularly if the developer has lesser power, as in Case 3 for (SS). The opportunistic behaviour of the supporter is high, particularly if it has more power, as we see (B/S) reaps benefit (economic and environmental values) without investing in relationship development. Upstream in the RSC, the relationship is more aligned (as in Case 2), as the partners reduce their opportunistic behaviour and instead become symbiotic (in Case 1) by investing more equally.

Proposition 2 deals with the knowledge or information sharing routines in RSC context. The RSC literature instantiate how seamless information integration can be built, first by constituting IT-facilitated data exchanges to develop trust, that can further intensify the relationship towards joint strategic processes or capacity design (Aitken and Harrison, 2013; Olorunniwo and $\mathrm{Li}, 2010$ ). Our study at the RSC level extends this finding by highlighting the influence of nature of relationship on the mechanism for knowledge or information sharing. In particular, proposition 2a shows that the arm's-length relationships at the downstream RSC that are more opportunistic in nature, adopt informal inter-personal ways to avoid risky investment, as in Case 3. In contrast to RT propositions (cf. Dyer and Singh, 1998; Lavie, 2006), our study formulates the role of such informal relationship not only in long-term 
orientations like strategic alliances, but also in highly transactional relations in order to mitigate opportunism. Once the collaborative norms have been established and formalized through knowledge codification (as in Case 2), the complex knowledge exchange is much simplified through the establishment of knowledge exchange platforms (in Case 1). Such joint integration effort in upstream RSC both formalizes and amplifies the relationship, and demands codification of information/data exchanges, as seen in Case 2. This case shows evidence of integration efforts, either to co-create training procedures or to routinize tacit skills, required to align the incentives. Proposition $2 \mathrm{~b}$ is consistent with the findings of Son et al. (2015) which highlights that one-sided development or sharing of information leads to higher relative bargaining power (Lavie, 2006).

Proposition 3 deals with resource complementarities, in line with Dyer and Singh (1998), which highlights that the potential to generate relational rent increases if collective resource endowment includes specialized expertise and intangible assets, e.g. reputation or information-rich positioning, as evidenced in all three cases irrespective of their positioning in the RSC. However downstream in the RSC, where the opportunism is high, the partners in the arm's-length relationship try to exploit the intangible asset in order to influence their bargaining power instead of generating relational rent. Particularly if the dyad supporter possesses such strategic complementary resource until the relationship is more synergistic, the possibility to exploit the intangible asset for creating more opportunism is higher as evidenced in Case 3.

Proposition 4 refers to instruments used for RSC governance. In RT, Dyer and Singh (1998) propose that informal safeguards (e.g. trust) are more rent earning compared to the formal ones and have more power in deterring potential opportunism. While the RSC literature acknowledges the role of goodwill and competence trusts (Aitken and Harrison, 2013; Jayaraman and Luo, 2007), this study further highlights how the nature of trust building varies along the RSC. Regardless of the positioning of the relational dyad along the RSC stages, presence of trust is of crucial importance; consistent with the seminal work of Sako (1992) it can be distinguished as (competence) trust in Case 3 to ensure high material and delivery service quality at low cost for both partners, (contractual) trust in Case 2 adhering to specifically written codes of conducts for maintaining high standards in the business transaction, and (goodwill) trust in Case 1 to mutually develop the take-back scheme (without any legal obligations). In addition to trust building, proposition 4 uncovers the role of different safeguards additionally used in these RSC relationships. In downstream RSC, the motivation to make investments in safeguarding instruments for arms-length relationship is deterred by the higher risks of partner opportunism. Thus building inter-personal ways (as in Case 3) is considered less vulnerable. On the other hand in upstream RSC, even though the relational governance is more symbiotic in nature underpinned by goodwill trust, the role of additional safeguards can be justified by the fear of malfeasance that trust may contribute to opportunism without the presence of adequate monitoring or coordination mechanisms and an overall misalignment in interests can emerge undetected. This is consistent with the notion of dual role of trust or "trust paradox" as both supportive and detrimental features of relationship (Day et al., 2013; Dyer and Singh, 1998). At the extreme, partners may devise specific ways to cheat one another under the veil of close relations, for example, $(\mathrm{R})$ may start hiding profits to seek $(\mathrm{B} / \mathrm{S})$ 's financial support or $(\mathrm{B} / \mathrm{S})$ may not give good recycled materials to $(\mathrm{R})$. Use of additional self-enforced formal contracts in RSCs referred also in Jack et al. (2010), like that of the cost-neutral contracts, can act as both monitoring and rewarding tools.

\subsection{Implications for $\mathrm{RSC}$ research and practice}


Our research offer academics a new perspective on multidimensional value creation through RSC relationships. Firstly it showcases how such multidimensional values are created relationally by drawing the lens of RT (Dyer and Singh, 1998), as the nature of relationship existing in RSCs differs. More specifically, the nature of relationship seem to vary between upstream and downstream RSCs, as we observe the presence of more opportunistic arm'slength relations downstream, while more symbiotic relations prevail upstream. Such relational nature characterizes the role played by the RSC actors (developer or supporter), in terms of their relative proportion of investment or effort into the relational asset, and together with the concept of power asymmetry (Cox, 1999; Nyaga et al., 2013), further explains the source of opportunism.

Additionally, our research propositions reveal the key differences in relationship characteristics and sources of value creation, between downstream and upstream RSC. In downstream relationships that are opportunistic in nature, value is created relationally using inter-personal ways of knowledge sharing, and through use of informal safeguards. In contrast upstream relationships are more symbiotic where value is created relationally through more seamless (and routinized) knowledge sharing practices (as also evidenced in $\mathrm{Li}$ and Olorunniwo, 2008; Olorunniwo and Li, 2010), and additional use of more formal transactionspecific controls or financial incentives as safeguarding instruments (evidenced through propositions 2 and 4). In comparison to a symbiotic relationship, the opportunistic ones are however prone to greater bargains and transaction risks if intangible assets are possessed equally by both partners (revealed through proposition 3). We believe that if the relationship is opportunistic, it is better if the supporter does not possess critical intangible assets that can further aggravate the opportunism, until the relationship is more aligned. Further for academics this opens opportunities to understand the relational dynamics, and their implications on handling multiple relations and processes simultaneously (Autry et al., 2014), embedded in complex RSCs.

The results of this study provide relevant insights to RSC practitioners, particularly to those who work in industries with complex global reverse supply chain, in which multiple value incentives and different natures of relationships exist. In line with Sandberg et al. (2018), the study reveals a number of values (economic, information, image, environmental and customer) present in the RSC (as shown in Table 3) - however this is more multi-dimensional in the upstream RSC compared to downstream where economic value creation outweighs other value forms. Further the study shows how these values are created through RSC relationships, and are differently distributed among the members of the RSC. For practitioners it becomes evident that the scope of value beyond the economic ones is important to include for effective RSC practices.

The findings from the study can specifically help practitioners to reduce opportunism present in the RSC. For example, to build more symbiotic RSC relationships upstream practitioners, i.e. those from collecting retailers and charities or global sorting companies, should jointly develop routines for knowledge sharing even though it may require higher investments initially. Only by doing so, more seamless interchanges can be facilitated - a move that we documented through Proposition 2. Similarly, to reduce opportunism downstream in the RSC, practitioners from the sorting and processing firms (in the Global South) may develop deeper personal communications and relationship-building traits to ward-off any opportunistic bargaining - as visible in case 3 . 
Further, except for an understanding of optimal relational characteristics in RSC, the results offer practitioners valuable insights for how to position, and at the end of the day proactively manage multiple collaborative relationships in a RSC. For example, the charities are engaged in diverse relationships (e.g. logistics outsourcing, strategic alliance, etc.) and with many members (e.g. brokers/sorters, second-hand retailers, etc.). With the knowledge of each relational characteristic (revealed in Figure 2), it would be easier to better position themselves in the RSC, understand the inter-dyad influences, and create higher relational value.

\subsection{Limitations and further research}

Our conclusions are limited by the consideration of only three consolidated cases, even though they provide in-depth perspectives. Future research should be conducted to test the propositions by using more cases, and preferably paired cases to avoid data inconsistency and biasness that may be resultant of such consolidation by authors. Additionally more quantitative survey-based methods could be used for proposition testing, however to conduct more multi-sectorial RSC study industry characteristics must be taken into consideration as either mediators and external influencers, which were not considered in this study given the choice of one specific RSC sector even though the extremities of the cases presented is suitable for theory elaboration as per methodology discourse. Another limitation of this study is the development of propositions per each RT source. In fact these sources of relational rent are inter-related, but we have simply followed the proposition generation procedure as in the parent works of Dyer and Singh (1998) and Lavie (2006) to derive them. Finally, even though we have compared and contrasted the three cases for deriving propositions, we have restricted ourselves in dealing with the inter-dyad relations and influences at the network level. This seeks exploration of industrial network theories to understand the dynamics.

\section{Notes}

1. Cost neutral agreement is a common financial format underpinning take-back schemes, as can be seen in several European waste packaging collection programmes, e.g. Deposit and Return Scheme (DRS) (Lawlor, 2018). However, the term has slightly different interpretations in different industries, based on who bears the responsibility for the set-up and logistics costs, and how it is arranged (ibid). In the fashion industry context as described here, cost-neutrality of the take-back schemes are commonly defined from the retailers' standpoint that bears the store set-up and logistics costs as their extended responsibility, and gets paid per unit volume of collection by the partnering broker/sorter. Profit made by selling the used clothes to the broker/sorter has to be donated for social causes, while losses encountered are compensated by the broker/sorter.

2. Trading subsidiaries are separate legal entities owned and controlled by one or more charities. Commonly, charities setup a trading subsidiary in order to undertake non-primary purpose trading as a way to generate income without the need to pay tax on the profits. The subsidiary conducts the trading to generate profits, which can be donated back to the charity as gift aid. For a detailed understanding of its functioning, see OSCR (2018).

3. Trade licenses are commonly observed in used textile and clothing industry in Asia and Africa that faces threat to the domestic textile industry from competition via cheap imports from Europe and elsewhere. These licenses are imposed by the respective government of importing countries in order to restrict (and control) the import volume, and differs slightly in their specificities, i.e. in terms of coverage of type of products, tax tariff/import duties, certification requirements, and bureaucracy. Watson et al. (2016, pp- 52-53) provides a comparison of the restrictions in selected countries in Africa, Latin-America, Middle-East and Asia. Comparable 
permits/licenses (as observed in India) are required by units operating in SEZs or EPZ (Export Processing Zones) in South Africa, Namibia, and Pakistan.

\section{References}

Acharya, N. (2015), "India Emerges Top Importer of Used Clothes”, Business Standard, Kolkata,

10 October, available at: www.business-standard.com/article/current-affairs/india-emergestopimporter-of-used-clothes-115100800540_1.html (accessed 11 April 2019).

Aitken, J. and Harrison, A. (2013), "Supply governance structures for reverse logistics systems", International Journal of Operations \& Production Management, Vol. 33 No. 6, pp 745-64.

Aitken, J. and Murray, A. (2010), "Crash repairs in the UK: reusing salvaged parts in car repair centres", International Journal of Logistics: Research and Applications, Vol. 13 No. 5, pp. 359-72.

Autry, C.W., Williams, B.D. and Golicic, S. (2014), "Relational and process multiplexity in vertical supply chain triads: An exploration in the U.S. restaurant industry", Journal of Business Logistics, Vol. 35 No. 1, pp. 52-70.

Barratt, M., Choi, T. and Li., M. (2011), "Qualitative case studies in operations management: trends, research outcomes, and future research implications", Journal of Operations Management, Vol. 29 No. 4, pp. 329-42.

Beh, L-S., Ghobadian, A., He, Q., Gallear, D. and O'Regan, N. (2016), "Second-life retailing: a reverse supply chain perspective", Supply Chain Management: An International Journal, Vol. 21 No. 2, pp.259-72.

Bernon, M., Rossi, S. and Cullen, J. (2011), "Retail reverse logistics: a call and grounding framework for research", International Journal of Physical Distribution \& Logistics Management, Vol. 41 No. 5, pp. 484-510.

Brooks, A. (2013), "Stretching global production networks: the international second-hand clothing trade", Geoforum, Vol. 44 No. 1, pp. 10-22.

Chan, H. (2007), "A pro-active and collaborative approach to reverse logistics - a case study", Production Planning \& Control, Vol. 18 No. 4, pp. 350-60.

Cox, A. (1999), "Power, value, and supply chain management", Supply Chain Management: An International Journal, Vol. 4 No. 4, pp. 167-75.

Daugherty, P., Richey, G., Hudgens, B. and Autry, C. (2003), "Reverse logistics in the automobile aftermarket industry", The International Journal of Logistics Management, Vol. 14 No. 1, pp. 4962.

Day, M. Fawcett, S.E., Fawcett, A.M., and Magnan, G.M. (2013), "Trust and relational embeddedness: Exploring a paradox of trust pattern development in key supplier relationships", Industrial Marketing Management, Vol. 42 No. 2, pp. 152-65.

Dyer, J.H. and Singh, H. (1998), "The relational view: cooperative strategy and sources of interorganizational competitive advantage, The Academy of Management Review, Vol. 23 No. 4, pp. 660-79.

Eisenhardt, K.M. and Graebner, M.E. (2007), "Theory building from cases: opportunities and challenges", Academy of Management Journal, Vol. 50 No. 1, pp. 25-32.

Ellram, L.M. (1996), "The use of the case study methods in logistics research", Journal of Business Logistics, Vol. 17 No. 2, pp. 93-138.

Erol, I., Velioğlu, M.N. Şerifoğlu, F.S., Büyüközkan, G., Aras, N., Çakar, N.D. and Korugan, A. (2010), "Exploring reverse supply chain management practices in Turkey", Supply Chain Management: An International Journal, Vol. 15 No. 1, pp. 43-54. 
Fawcett, S.E., Waller, M., Miller, J.W., Schwieterman, M.A., Hazen, B.T. and Overstreet, R.E. (2014), "A trail guide to publishing success. Tips on writing influential conceptual, qualitative and survey research", Journal of Business Logistics, Vol. 35 No. 1, pp. 1-16.

Fleischmann, M. and Kuik, R. (2003), "Production, manufacturing and logistics: on optimal inventory control with independent stochastic item returns", European Journal of Operational Research, Vol. 151 No. 1, pp. 25-37.

Flyvbjerg, B. (2006), "Five misunderstandings about case-study research", Qualitative Inquiry, Vol. 12 No. 2, pp. 219-45.

Guide, V.D.R. and Van Wassenhove, L.N. (2009), "OR FORUM - The evolution of closed-loop supply chain research", Operations Research, Vol. 57 No. 1, pp. 10-18

Hazen, B., Hall, D. and Hanna, J. (2012), "Reverse logistics disposition decision-making: developing a decision framework via content analysis", International Journal of Physical Distribution \& Logistics Management, Vol. 42 No. 3, pp. 244-74.

Huang, Y-C., Wu, Y-C., J. and Rahman, S. (2012), “The task environment, resource commitment and reverse logistics performance: evidence from the Taiwanese high-tech sector", Production Planning \& Control, Vol. 23 No. 10-11, pp. 851-63.

Jack, E.P., Powers, T.I. and Skinner, L. (2010), "Reverse logistics capabilities: antecedents and cost savings", International Journal of Physical Distribution and Logistics Management, Vol. 40 No. 3, pp. 228-46.

Jayaraman, V. and Luo, Y. (2007), "Creating competitive advantages through new value creation: A reverse logistics perspective", Academy of Management Perspectives, Vol. 21 No. 2, pp. 56-73.

Jayaraman, V., Ross, A. and Agarwal, A. (2008), "Role of information technology and collaboration in reverse logistics supply chains", International Journal of Logistics Research and Applications, Vol. 11 No. 6, pp. 409-25.

Ketokivi, M. and Choi, T. (2014), "Renaissance of case research as a scientific method", Journal of Operations Management, Vol. 32 No. 5, pp. 232-40.

Ketokivi, M. (2006), "Elaborating the contingency theory of organizations: the case of manufacturing flexibility strategies", Production and Operations Management, Vol. 15 No. 2, pp. 215-28.

Kovács, G. and Spens, K.M. (2005), "Abductive reasoning in logistics research", International Journal of Physical Distribution and Logistics Management, Vol. 35 No 2, pp. 132-44.

Larsen, S.B., Masi, D., Jacobsen, P. and Godsell, J. (2018), "How the reverse supply chain contributes to a firm's competitive strategy: a strategic alignment perspective", Production Planning \& Control, Vol. 29 No. 6, pp. 452-63.

Lau, K.H. and Wang, Y. (2009), "Reverse logistics in the electronic industry of China: a case study", Supply Chain Management: An International Journal, Vol. 14 No. 6, pp. 447-65.

Lavie, D. (2006), "The competitive advantages of interconnected firms: An extension of the resourcebased view", Academy of Management Review, Vol. 31 No. 3, pp. 638-58.

Li, X., and Olorunniwo, F. (2008), "An exploration of reverse logistics practices in three companies", Supply Chain Management: An International Journal, Vol. 13 No. 5, pp. 381-86.

Miles, M.B. and Huberman, A.M. (1994), Qualitative data analysis: An expanded sourcebook, 2 Edition, Sage Publications, Thousand Oaks.

Morgan, T.R., Richey Jr, R.G. and Autry, C.W. (2016), "Developing a reverse logistics competency: The influence of collaboration and information technology", International Journal of Physical Distribution \& Logistics Management, Vol. 46 No. 3, pp. 293-315.

Nyaga, G.N., Lynch, D.F., Marshall, D. and Ambrose, E. (2013), "Power asymmetry, adaptation and collaboration in dyadic relationships involving a powerful partner", Journal of Supply Chain Management, Vol. 49 No. 3, pp. 42-65. 
Olorunniwo, F. and Li, X. (2010), "Information sharing and collaboration practices in reverse logistics", Supply Chain Management: An International Journal, Vol. 15 No. 6, pp. 454-62.

O'Reilly, S. and Kumar, A. (2016), "Closing the loop: an exploratory study of reverse ready-made garment supply chains in Delhi NCR", The International Journal of Logistics Management, Vol. 27 No. 2, pp. 486-510.

Pal, R. (2017), "Value creation through reverse logistics in used clothing networks", The International Journal of Logistics Management, Vol. 28 No. 3, pp. 864-906.

Patton, M.Q. (2002), Qualitative Research and Evaluation Methods, Sage Publication, Thousand Oaks, CA.

Richey, R.G., Genchev, S.E. and Daugherty, P.J. (2005), "The role of resource commitment and innovation in reverse logistics performance", International Journal of Physical Distribution \& Logistics Management, Vol. 35 No. 4, pp. 233-57.

Sako M. (1992), Prices, Quality and Trust: Interfirm relations in Britain and Japan, Cambridge University Press, Cambridge.

Sandberg, E. Pal, R. and Hemilä, J. (2018), "Exploring value creation and appropriation in the reverse clothing supply chain", The International Journal of Logistics Management, Vol. 29 No. 1, pp. 90109.

Schenkel, M.M., Caniëls, M., Krikke, H., and Van Der Laan, E. (2015), "Understanding value creation in closed loop supply chains - past findings and future directions", Journal of Manufacturing Systems, Vol. 37 (April), pp. 729-45.

Simpson, D. (2010), "Use of supply relationships to recycle secondary materials", International Journal of Production Research, Vol. 48 No. 1, pp. 227-49.

Skinner, L., Bryant, P. and Richey, G. (2008), "Examining the impact of reverse logistics disposition strategies", International Journal of Physical Distribution and Logistics Management, Vol. 38 No. 7, pp. 518-39.

Son, Y., Kim, T. and Omar, M. (2015), "The beneficial effect of information sharing in a two-stage reverse supply chain", International Journal of Procurement Management, Vol. 8 No. 6, pp. 608709.

Statista (2019), "Second-hand retail in the UK - Statistics \& Facts", The Statistic Portal, U.K., available at: https://www.statista.com/topics/4593/second-hand-retail-in-the-united-kingdom-uk/ (accessed 10 April 2019).

Touboulic, A. and Walker, H. (2015), "Love me, love me not: A nuanced view on collaboration in sustainable supply chains", Journal of Purchasing \& Supply Management, Vol. 21 No. 3, pp. 178191.

Voss, C., Tsikritsis, N., Frohlich, M. (2002), "Case research in Operations Management", International Journal of Operations and Production Management, Vol. 22 No. 2, pp. 195-219.

Xie, Y. and Breen, L. (2012), "Greening community pharmaceutical supply chain in UK: a cross boundary approach", Supply Chain Management: An International Journal, Vol. 17 No. 1, pp. 4053.

Yin, R.K. (2009), Case Study research: design and methods, Sage Publications, London.

\section{Further Reading}

Lawlor, D. (2018), "L\&RS Note: Cost Estimate - Waste Reduction Bill 2017 and related proposals", available at: https://data.oireachtas.ie/ie/oireachtas/libraryResearch/2018/2018-05-14_1-rs-notecost-estimate-waste-reduction-bill-2017-and-related-proposals_en.pdf (accessed 12 April 2019) 
OSCR (2018), “Trading Subsidiaries”, available at: https://www.oscr.org.uk/guidance-andforms/charities-and-trading-guide/2-trading-subsidiaries/ (accessed 10 April 2019)

Watson, D., Palm, D., Brix, L., Amstrup, M., Syversen F. and Nielsen, R. (2016), "Exports of Nordic Used Textiles: Fate, benefits and impacts", Nordic Council of Ministers, TemaNord 2016:558, available at: https://norden.diva-portal.org/smash/get/diva2:1057017/FULLTEXT03.pdf (accessed 7 February 2018) 
PROPOSITION 1

On Relative proportion of investment/effort into relational asset

PROPOSITION 2

On Knowledge or information sharing routines

PROPOSITION 3

On Resource complementarities in terms of intangible assets

\section{PROPOSITION 4}

On Use of governance/safeguarding instruments
More equal investment/effort yielding symbiotic relationship

i

More seamless (and routinized) knowledge exchanges established

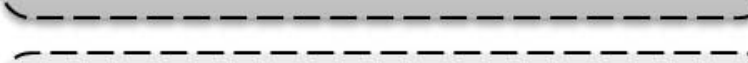
(1)

Higher rent generation potential through collective intangible asset endowment

Formal transaction-specific controls or financial incentives (in addition to goodwill trust)
Disproportionate investment/effort yielding higher opportunism, particularly if developer possess lesser power

- - - - - - - - - - - - - Informal inter-personal relations to avoid risky investment into arm's-length relationships Higher chances of exploitation of intangible assets to generate bargaining power by supporter

Inter-personal relation as informal safeguard (in addition to competence trust) 
Table 1.

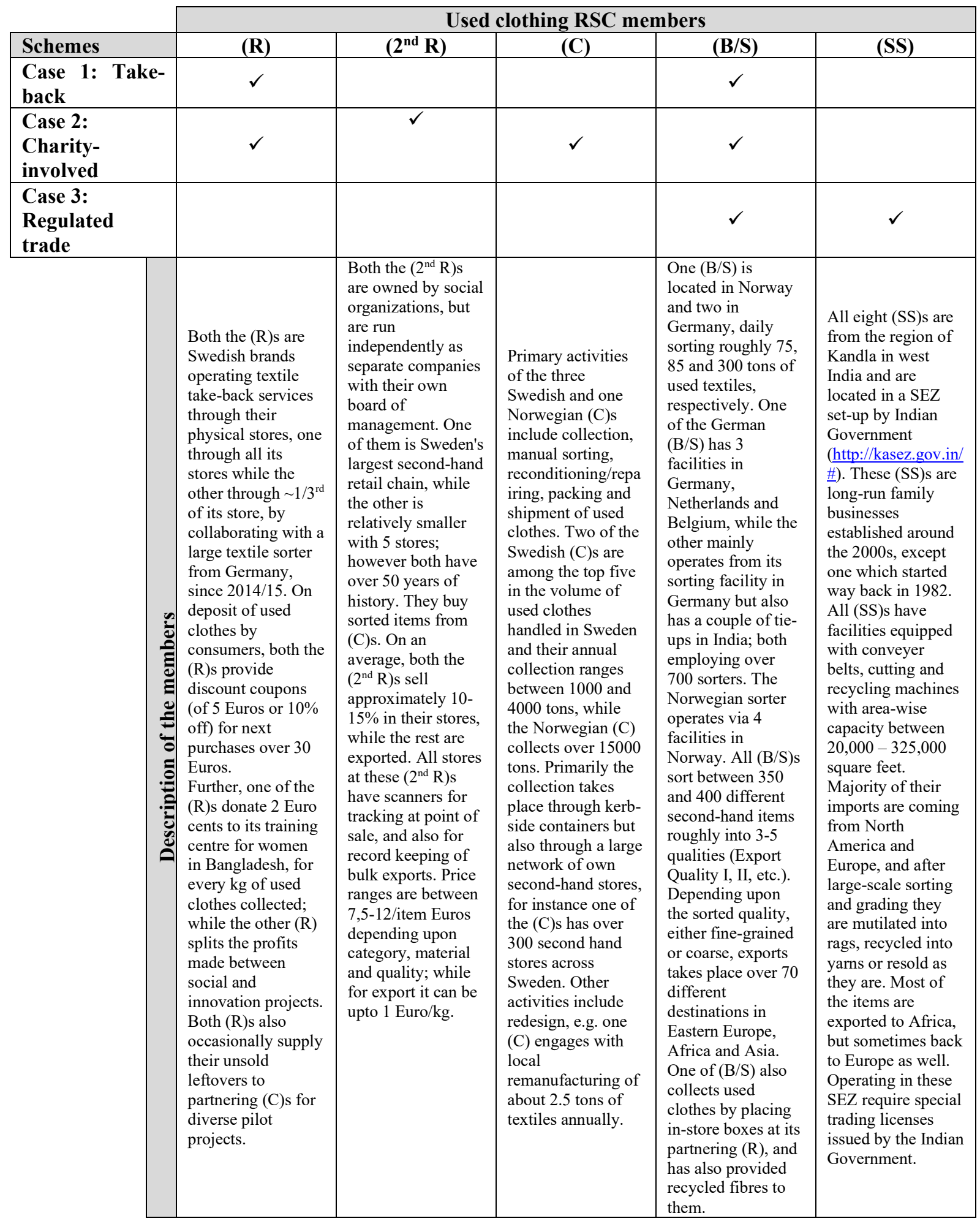


Table 2.

\begin{tabular}{|c|c|c|c|}
\hline Members & Interviews & Site visits & Documents \\
\hline (R) & 2 interviews (71 minutes) & $\begin{array}{l}2 \text { visits to local stores with } \\
\text { take-back collection bins }\end{array}$ & $\begin{array}{l}\text { Marketing materials, Standard terms } \\
\text { and conditions related to take-back } \\
\text { schemes, Online materials (videos } \\
\text { and news on take-back) }\end{array}$ \\
\hline$\left(2^{\text {nd }} R\right)$ & $\begin{array}{l}4 \quad \text { interviews } \quad(241 \\
\text { minutes })\end{array}$ & $\begin{array}{l}3 \text { visits, one each to } \\
\text { second-hand store, pre- } \\
\text { sorting plant and redesign } \\
\text { studio }\end{array}$ & Online materials (videos and news) \\
\hline (C) & $\begin{array}{l}5 \text { interviews } \\
\text { minutes) }\end{array}$ & $\begin{array}{l}3 \text { visits to pre-sorting } \\
\text { facilities }\end{array}$ & $\begin{array}{l}\text { Marketing materials, Online materials } \\
\text { (videos and news) }\end{array}$ \\
\hline$(\mathrm{B} / \mathrm{S})$ & 2 interviews ( 85 minutes) & $\begin{array}{l}1 \text { visit to global sorting } \\
\text { headquarter }\end{array}$ & $\begin{array}{l}\text { Project management plans, Standard } \\
\text { terms and conditions related to take- } \\
\text { back schemes, Marketing materials, } \\
\text { Online materials (videos and news) }\end{array}$ \\
\hline (SS) & $\begin{array}{l}4 \quad \text { interviews } \\
\text { minutes) }\end{array}$ & $\begin{array}{l}8 \text { visits to manual sorting } \\
\text { facilities }\end{array}$ & Marketing materials, Website \\
\hline
\end{tabular}


Table 3.

\begin{tabular}{|c|c|c|c|}
\hline $\begin{array}{c}\text { Relational } \\
\text { sources }\end{array}$ & Case 1 : Take-back & Case 2: Charity-involved & Case 3: Regulated trade \\
\hline $\begin{array}{l}\text { Relation- } \\
\text { specific } \\
\text { assets }\end{array}$ & $\begin{array}{l}\text { High level of joint efforts and } \\
\text { investments in upscaling the } \\
\text { scheme and relational } \\
\text { benefits. } \\
\text { (B/S) invests in easy, in-store } \\
\text { collection system that leads to } \\
\text { higher customer convenience } \\
\text { and collection volume for (R) } \\
\text { (customer and economic } \\
\text { values). } \\
\text { (R) communicates the take-back } \\
\text { vision (of instilling higher } \\
\text { reuse) to consumers and } \\
\text { incentivizes by offering } \\
\text { vouchers. Consumer feedback } \\
\text { improves the collection } \\
\text { volume (economic and } \\
\text { information values). }\end{array}$ & $\begin{array}{l}\text { Partner originating the dyad } \\
\text { typically invests more in } \\
\text { efforts and assets, though } \\
\text { some synergy exists. } \\
\text { (C)'s trading subsidiary } \\
\text { develops specific } \\
\text { relationships with its buyers, } \\
\text { i.e. } 2^{\text {nd }} \text { (R), and offers them } \\
\text { good quality, branded items } \\
\text { (economic value). The } \\
\text { subsidiary ensures low } \\
\text { transaction risks and } \\
\text { competitive price points. } 2^{\text {nd }} \\
\text { (R) gathers local market } \\
\text { knowledge (information } \\
\text { value) to support. } \\
\text { In strategic alliance dyad, (B/S) } \\
\text { invests in sorting facility to } \\
\text { improve process } \\
\text { effectiveness by adapting to } \\
\text { local needs (economic value). } \\
\text { (C) with government subsidy, } \\
\text { organizes collection and } \\
\text { provides understanding of } \\
\text { local market needs (economic } \\
\text { and information value). }\end{array}$ & $\begin{array}{l}\text { Large difference in efforts and } \\
\text { investment between } \\
\text { partners. One who } \\
\text { originates the dyad mostly } \\
\text { invests while the other gets } \\
\text { freeride. } \\
\text { (SS)s invest in trade licenses in } \\
\text { SEZs to enhance } \\
\text { legitimacy/trust with (B/S) } \\
\text { (image value). The licenses } \\
\text { exempt both members from } \\
\text { paying duties and thus reduce } \\
\text { total costs (economic value). } \\
\text { Further, (SS)s' locational } \\
\text { advantage facilitates vertical } \\
\text { integration to produce high } \\
\text { quality recycled material for } \\
\text { (B/S) (economic and } \\
\text { environmental values). }\end{array}$ \\
\hline $\begin{array}{l}\text { Knowledge- } \\
\text { sharing } \\
\text { routines }\end{array}$ & $\begin{array}{l}\text { Seamless transparency in } \\
\text { sharing information by dyad } \\
\text { partners. } \\
\text { (B/S) shares information on the } \\
\text { destination market and its } \\
\text { impact, thus building trust in } \\
\text { the collaboration. (R) } \\
\text { communicates this to } \\
\text { consumers to showcase } \\
\text { responsibility (image value). } \\
\text { (R) also shares consumer } \\
\text { feedback with (B/S) to assist } \\
\text { in building its market } \\
\text { intelligence (information } \\
\text { value). (B/S) further builds } \\
\text { (R)'s knowhow on textile } \\
\text { circular economy via an open } \\
\text { knowledge-sharing platform } \\
\text { (information and } \\
\text { environmental values). }\end{array}$ & $\begin{array}{l}\text { Joint knowledge creation } \\
\text { efforts specific to the dyad. } \\
\text { In (C)-(B/S) strategic alliance, } \\
\text { (C)'s know-how of the local } \\
\text { market characteristics and } \\
\text { (B/S)'s strategic sorting } \\
\text { parameters and skills } \\
\text { combines to create a unique } \\
\text { training program aimed to } \\
\text { enhance sorting effectiveness } \\
\text { (economic value). } \\
\text { Joint efforts taken to codify } \\
\text { tacit skills. } \\
\text { In (C)-(R) dyad, (C)'s effort in } \\
\text { codifying tacit } \\
\text { remanufacturing skills to } \\
\text { routinize the practice serve as } \\
\text { justification for high product } \\
\text { prices from (R) (economic } \\
\text { value). }\end{array}$ & $\begin{array}{l}\text { Informal social interaction in } \\
\text { the dyad. } \\
\text { (SS)s interact at personal level } \\
\text { to extract information on } \\
\text { material source and quality } \\
\text { (information value), and fetch } \\
\text { high volume. This triggers } \\
\text { incentives for higher profits } \\
\text { for both partners (economic } \\
\text { value). }\end{array}$ \\
\hline $\begin{array}{l}\text { Complemen } \\
\text { tary } \\
\text { resources } \\
\text { and } \\
\text { capabilities }\end{array}$ & $\begin{array}{l}\text { Process knowledge and skills } \\
\text { of the partner originating } \\
\text { the dyad supplements } \\
\text { reverse logistics capabilities } \\
\text { of both partners. } \\
\text { (B/S)'s knowledge and skills } \\
\text { related to value-adding } \\
\text { reverse logistics is crucial for } \\
\text { (R) to explore circular } \\
\text { business opportunities } \\
\text { (customer and environmental } \\
\text { values), and to showcase } \\
\text { extended responsibility } \\
\end{array}$ & $\begin{array}{l}\text { Process knowhow, skills and } \\
\text { image supplement reverse } \\
\text { logistics capabilities of both } \\
\text { partners'. } \\
\text { (C)'s process knowhow provides } \\
\text { (2nd } \mathrm{R} \text { ) and (B/S) access to } \\
\text { good quality material, scaling } \\
\text { opportunities and reduced } \\
\text { collection costs (economic } \\
\text { value). } \\
\text { Further, (C)'s local collection } \\
\text { knowhow complements } \\
\text { (B/S)'s sorting skills and } \\
\end{array}$ & $\begin{array}{l}\text { Information-rich position and } \\
\text { process knowledge } \\
\text { supplement reverse logistics } \\
\text { capabilities of both } \\
\text { partners, but potentials high } \\
\text { bargaining too. } \\
\text { (B/S)'s information-rich position } \\
\text { and praxis of reverse logistics } \\
\text { is key to suffice confidence in } \\
\text { the relationship thus reducing } \\
\text { partner search cost for (SS) } \\
\text { (information value). This } \\
\text { ensures smooth flow of high }\end{array}$ \\
\hline
\end{tabular}




\begin{tabular}{|c|c|c|c|}
\hline & $\begin{array}{l}\text { (image value). } \\
\text { (R)'s in-store collection supports } \\
\text { (B/S)'s cost-optimized } \\
\text { logistics to offer service } \\
\text { quality, volume and profit } \\
\text { (economic value). }\end{array}$ & $\begin{array}{l}\text { global distribution network to } \\
\text { achieve reverse logistics } \\
\text { efficiency (economic value). } \\
\text { In (C)-(R) dyad, (C)'s } \\
\text { philanthropic image reduces } \\
\text { consumer scepticism towards } \\
\text { (R)'s corporate responsibility } \\
\text { and sustainability campaigns } \\
\text { (customer value). } \\
\text { (R) ensures more monitoring } \\
\text { and reverse supply chain } \\
\text { organization along with (C)'s } \\
\text { process efficiency (economic } \\
\text { value). }\end{array}$ & $\begin{array}{l}\text { quality material (economic } \\
\text { value). } \\
\text { (SS)s' praxis and skills of value- } \\
\text { added reverse operations } \\
\text { ensures recycled material } \\
\text { quality for }(\mathrm{B} / \mathrm{S})(\text { economic } \\
\text { and customer values). } \\
\text { Higher chances of antagonistic } \\
\text { bargaining by }(\mathrm{B} / \mathrm{S}) \text {. }\end{array}$ \\
\hline $\begin{array}{l}\text { Effective } \\
\text { governance }\end{array}$ & $\begin{array}{l}\text { Cost-neutral financial } \\
\text { agreement safeguards the } \\
\text { contract, in addition to } \\
\text { goodwill trust. } \\
\text { Cost-neutrality provides } \\
\text { financial safeguard to (R), } \\
\text { reduces bargaining costs and } \\
\text { improves scale (economic } \\
\text { value), incentivizes extension } \\
\text { of CSR activities and green } \\
\text { image (image value). } \\
\text { Scale ensures access to large } \\
\text { volume of material/resources } \\
\text { for }(\mathrm{B} / \mathrm{S})(\text { economic value). }\end{array}$ & $\begin{array}{l}\text { Code of conduct influence } \\
\text { transaction-specific } \\
\text { contracts to uphold buyer- } \\
\text { seller trust. } \\
\text { In (C)-( } 2^{\text {nd }} \text { R) dyad, (C)'s } \\
\text { business specific code of } \\
\text { conduct influences the } \\
\text { transaction contracts to } \\
\text { ensure profit and traceability } \\
\text { (economic and information } \\
\text { values). Additionally this } \\
\text { reduces risks of illegalities } \\
\text { for all partners (image value). } \\
\text { (C)'s possession of official } \\
\text { rights to collect guarantees } \\
\text { trust in the relationship and } \\
\text { hedges from illegalities } \\
\text { (image value). }\end{array}$ & $\begin{array}{l}\text { Informal interaction enhances } \\
\text { trust built based on } \\
\text { operational abilities. } \\
\text { (SS)'s personal interaction } \\
\text { builds its brand (image value) } \\
\text { to enhance trust built between } \\
\text { both members through } \\
\text { improvement in service } \\
\text { quality and delivery regularity } \\
\text { (economic value). This allows } \\
\text { effective negotiation and } \\
\text { avoids risk. } \\
\text { Direct transitions established } \\
\left.\text { between (SS) and ( } 2^{\text {nd }} \mathrm{R}\right) \text { to } \\
\text { reduce bargains from (B/S), } \\
\text { which however increases } \\
\text { partner search cost. }\end{array}$ \\
\hline
\end{tabular}

